\title{
STARTUPS: ESTUDO DO PROCESSO DE ABERTURA E GERENCIAMENTO
}

\author{
STARTUPS: STUDY OPENING AND MANAGEMENT PROCESS
}

Data de submissão: 29/11/2016 Aceite: 30/06/2017

Kristina Kieling Figueira ${ }^{1}$

Tatiane de Andrade Neves Hörbe ${ }^{2}$ Katiuscia de Fátima Schiemer Vargas ${ }^{3}$ Emanuelly Comoretto Machado ${ }^{4}$ Gilnei Luiz de Moura ${ }^{5}$

\section{RESUMO}

Este estudo busca compreender o processo e as ações realizadas para a abertura e o gerenciamento de startups. Para isso, realizou-se uma pesquisa de caráter exploratório e qualitativo, utilizando como técnica de coleta de dados entrevistas semiestruturadas, com sete sócios/gestores de startups da cidade de Santa Maria, Rio Grande do Sul, baseadas no modelo de Reynolds (2000). Os resultados demonstraram que os gestores de startups levam de quatro a seis meses para formular a ideia do negócio e colocá-la em prática, com investimentos considerados por eles relativamente baixos. Ademais, verificou-se que as startups investigadas, com todo seu potencial inovador e de diferenciação em relação aos demais negócios, além de buscarem metodologias de gestão específicas e direcionadas à sua natureza e formação, também utilizam ferramentas de gestão tradicionais como o conhecido e disseminado plano de negócios. Notou-se, ainda, que startups se deparam com problemas típicos de aceitação dos clientes, falta de recursos financeiros, falta de conhecimento de gestão e excesso de burocracia dos órgãos públicos quando iniciam suas atividades e que seus gestores, embora tenham estilos orientados para a inovação e a praticidade, assim como uma gestão voltada para as pessoas, adotam postura reativa no que tange à identificação e resolução de problemas.

Palavras-chave: Startup. Empreendedorismo. Gestão. Inovação.

\footnotetext{
1 Possui Graduação em Administração pela Universidade Federal de Santa Maria e Mestrado pelo Programa de Pós-Graduação em Administração (PPGA/UFSM). Santa Maria. Rio Grande do Sul. Brasil. E-mail: kristinakieling@gmail.com

2 Possui Graduação em Administração pela Universidade Federal de Santa Maria. Mestre pelo Programa de Pós-Graduação em Administração - PPGA/UFSM. Atualmente é doutoranda pelo Programa de Pós-Graduação em Administração - PPGA/UFSM. Santa Maria. Rio Grande do Sul. Brasil. E-mail: tatianehorbe@gmail.com

3 Possui Graduação em Administração pela Universidade de Cruz Alta (UNICRUZ). Mestre em Administração pelo Programa de Pós-Graduação em Administração - PPGA/UFSM. Doutoranda pelo Programa de Pós-Graduação em Administração - PPGA/UFSM. Atualmente é professora Assistente na Universidade Federal do Pampa - Campus Sant'Ana do Livramento. Sant'Ana do Livramento. Rio Grande do Sul. Brasil. E-mail: kati_schiemer@yahoo.com.br

4 Possui Graduação em Administração pela Universidade Federal de Santa Maria. Mestranda em Administração pelo Programa de Pós Graduação em Administração da Universidade Federal de Santa Maria. Santa Maria. Rio Grande do Sul. Brasil. E-mail: emanuelly_ comoretto@yahoo.com.br

5 Possui graduação em Administração pela Universidade Federal de Santa Maria, mestrado em Administração pela Universidade Federal de Santa Catarina e doutorado em Administração pela Escola de Economia, Administração e Contabilidade da Universidade de São Paulo. Atualmente é Professor na Universidade Federal de Santa Maria. Santa Maria. Rio Grande do Sul. Brasil. E-mail: mr.gmoura. ufsm@gmail.com
} 


\begin{abstract}
This study aims to understand the process and actions performed to open and manage startups. For this, an exploratory and qualitative research was carried out using semi-structured interviews as data collection technique, with seven partners/managers of startups from the city of Santa Maria, Rio Grande do Sul, based on the Reynolds model (2000). The results showed that startups managers take from four to six months to formulate the idea of the business and put it into practice, with investments considered by them to be relatively low. In addition, it was verified that the investigated startups, with all their innovative and differentiation potential in relation to the other businesses, besides searching for specific management methodologies and directed to their nature and formation, also use traditional management tools like the known and disseminated business plan. It was also noticed that startups come across with typical problems of customers acceptance, lack of financial resources, lack of management knowledge and excessive bureaucracy of public agencies when they start their activities and that their managers, although they have styles oriented to the innovation and practicality, as well as people-oriented management, take a reactive stance on identifying and solving problems.
\end{abstract}

Keywords: Startup. Entrepreneurship. Management. Innovation

\title{
1 INTRODUÇÃO
}

Economia globalizada, consumidores mais exigentes e mudanças tecnológicas são exemplos de fatores que vêm influenciando o ambiente de negócios, tornando-o um cenário de competitividade, incerteza e complexidade e incentivando a busca contínua pelo desenvolvimento tecnológico. Frente a esse contexto, destaca-se o número cada vez maior de indivíduos que são capazes de reconhecer oportunidades de negócio e explorá-las. Trata-se de indivíduos estimulados pela criatividade e pela inovação, responsáveis pela criação de empresas com caráter inovador e que assumem um importante papel no cenário mercadológico, a partir da criação de novos modelos de negócios que irão contribuir para o desenvolvimento econômico e social do país, seja com a criação de empregos ou com o aumento da riqueza e a sua distribuição.

Essa é a retratação do perfil de empreendedores de startups, que utilizam a inovação contínua para criar empresas extremamente bem-sucedidas em pleno século XXI (MORAES; CAPELLARI, 2013). Uma definição atual para uma startup é a de empresas jovens, extremamente inovadoras em qualquer área ou ramo de atividade, que procuram desenvolver um modelo de negócio escalável e repetível (ABSTARTUPS, 2014). Ou seja, um modelo de negócio capaz de produzir um mesmo produto ou serviço em grande escala, sem que este sofra adaptações para cada tipo de cliente e sem que os custos acompanhem o crescimento da empresa (GITAHY, 2011).

A história das startups iniciou na década de 90 quando surgiu a bolha da internet nos Estados Unidos, também denominada bolha "ponto com". Esse foi o começo de muitas empresas de sucesso, tais como Google ${ }^{\circledR}$, Ebay $^{\circledR}$ e Amazon ${ }^{\circledR}$. Porém, no Brasil, o empreendedorismo startup só passou a ser conhecido nos anos de 1999 a 2001 (GITAHY, 2011). Desde então, tem se verificado um grande crescimento das startups no país, sendo mais de 2.600 formalmente registradas no banco de dados da Associação Brasileira de Startups, fundada em junho de 2011 (STARTUPBASE, 2014).

Entretanto, apesar desse crescimento, o ambiente de negócios para as startups no Brasil ainda exibe muitas dificuldades, com destaque à excessiva carga tributária, aos custos trabaIhistas elevados, aos baixos incentivos a novos negócios e à alta mortalidade de empresas nos primeiros anos de vida. Somado a isso, há a dificuldade de acesso aos financiamentos, originada pelo fato de que, por tratar-se de negócios inovadores, com mercado incerto, tais negócios não oferecem quaisquer tipos de garantia aos investidores (NAGAMATSU; BARBOSA; REBECCHI, 2013). 
O ambiente de incerteza no qual são desenvolvidas essas empresas acaba por impactar, também, o gerenciamento das startups. Nesse ambiente, conforme Rogers (2011), com frequência, os empreendedores de startups precisarão tomar decisões, como, por exemplo, determinar a demanda do mercado por um produto ou serviço recém-desenvolvido, sem ter informações adequadas nem completas. Nesse sentido, os métodos tradicionais de gerenciamento adotados por companhias já existentes não têm tanta eficácia no contexto dessas empresas nascentes.

Diante do exposto, surgiu o interesse pela temática do presente trabalho, cujo objetivo consiste em compreender o processo e as ações realizadas para abertura e gerenciamento de startups do interior do estado do Rio Grande do Sul. Para atender ao objetivo proposto, este artigo aborda, no referencial teórico, a noção de startups, o surgimento e a evolução dessas empresas no Brasil, as metodologias existentes para implantação de startups e as dificuldades de abertura e gerenciamento dessas empresas. Posteriormente, apresentam-se o método de pesquisa adotado, a análise dos resultados e as considerações finais.

\section{STARTUPS: DEFINIÇÕES, EVOLUÇÃO E CONSIDERA- ÇÕES SOBRE GESTÃO}

As startups desempenham um papel fundamental na melhoria das eficiências econômicas e são um fonte significativa de muitas inovações (GRUBER et al., 2008; HUNT, 2013). 0 número de startups que está nascendo diante das necessidades da sociedade está crescendo e despejando no mercado uma gama cada vez maior de produtos e serviços (INFOMONEY, 2014).

Segundo dados da "Anjos do Brasil", organização sem fins lucrativos que reúne investidores para pequenas empresas, entre junho de 2012 e julho de 2013, o investimento destinado a startups cresceu $25 \%$ no Brasil, somando $R \$ \$ 19$ milhões de reais. O amadurecimento e o crescimento dessas empresas, no país, são reflexos do apoio e das ações focadas a esse tipo de empreendimento, ações que por muito tempo eram direcionadas para startups desenvolvidas no Vale do Silício na Califórnia, Estados Unidos, onde nasceram empresas como o Google ${ }^{\circledR}$ e o Facebook $^{\circledR}$ (ZACHARY, 2012).

Para Gitahy (2010), existem muitas definições em torno desse termo e novo modelo de negócio, mas, segundo o autor, a mais atual define uma startup como um grupo de pessoas à procura de um modelo de negócios repetível e escalável, trabalhando em condições de extrema incerteza. Ou seja, capaz de entregar o mesmo produto de forma potencialmente ilimitada, com crescimento constante, sem alterar seu modelo de negócios, tendo em vista um cenário ausente de garantias de aprovação ou estabilidade no mercado (GITAHY, 2010).

O modelo de negócios é como a startup gera valor, ou seja, como transforma seu trabalho em dinheiro. Osterwalder e Pigneur (2010) descrevem o modelo de negócio como a forma pela qual uma organização cria, entrega e captura valor, sendo essencial para o crescimento "sustentável" de um negócio. Um dos modelos de negócios da Google ${ }^{\circledR}$, por exemplo, é cobrar por cada clique nos anúncios mostrados nos resultados de busca, mesmo modelo utilizado pelo Buscapé.com ${ }^{\circledast}$ (SEBRAE, 2014).

Desse modo, o modelo de negócios de startups é reconhecido por estas estarem vinculadas à tendência de serem pequenas, mas sempre buscando novidades. No entanto, o seu fator limitante seria o acesso a recursos adequados. A escassez desses recursos obriga as empresas que estão na fase inicial a procurarem parceiros externos para o desenvolvimento e a comercialização de seus produtos (TEECE, 2010; ESTEVE-PÉREZ, RODRÍGUEZ, 2013). Conforme ressaltam Usman e Vanhaverbeke (2017), as startups, por serem incapazes de mobilizar os recursos sufi- 
cientes, acabam optando pela abertura dos seus processos e pelo desenvolvimento de parcerias com outras empresas para a adoção de inovações abertas.

Na visão de para Longhi (2011), startups são pequenas empresas montadas em casa ou em faculdades e que recebem pequenos aportes de capital. Elas exploram áreas inovadoras de determinado setor (mais comumente de tecnologia), possuindo uma aceleração de crescimento muito alta já nos primeiros meses de existência em virtude de investimentos feitos por fundos de investimento especializados. Assim, uma startup deve, por meio das suas ideias, construir produtos, medir como os clientes respondem e aprender a manter o rumo ou mudar de direção, tentando novas hipóteses sem perder a posição conquistada. $O$ objetivo é que as startups se concentrem em minimizar o tempo total desse circuito de reação para que mais rapidamente consigam obter uma aprendizagem validada, evitando os habituais desperdícios (RIES 2012; MAURYA, 2010).

Um aspecto observado por Ries (2005) é que nem toda empresa nova, em estágio inicial, pode ser considerada startup. De acordo com o autor, abrir uma nova empresa, exatamente igual a um negócio existente, copiando modelo de negócios, precificação, cliente-alvo e produto, pode ser um investimento econômico atraente, mas não é uma startup, pois seu sucesso depende somente da execução. Hermanson (2011), por sua vez, ressalta que startups não são necessariamente somente empresas de tecnologia; mas toda e qualquer empresa em fase de constituição. Esse tipo de empreendedorismo acontece mais na área da tecnologia porque os custos são mais baixos para criar uma empresa de software do que uma indústria.

Uma das principais diferenças entre startups e empresas tradicionais está na fase inicial da empresa. Enquanto que nas empresas tradicionais se aconselha a fazer um plano de negócios minucioso, ver a viabilidade e depois colocar em execução, o plano nas startups, basicamente, é definido por meio tentativa e erro, de modo que o empreendedor tem uma hipótese e vai a campo ver como esta é recepcionada no mercado (ALBERONE; CARVALHO; KICORVE, 2012). Segundo Blank e Dorf (2012), startups não são simplesmente versões menores de grandes empresas, motivo pelo qual uma empresa iniciante, ligada a qualquer tipo de negócio, que não esteja focada na inovação de produtos ou serviços e, portanto, dispensada quanto aos riscos de incertezas, não é uma startup.

Como alternativas ao tradicional plano de negócios, foram criadas algumas metodologias próprias para essas empresas. Contudo, por se tratar de startups, empreendedores desse perfil de empresa não sabem qual metodologia estão utilizando ou, até mesmo, se precisam utilizar alguma metodologia (MORAES; CAPELLARI, 2013). Uma pesquisa realizada pela Harvard Business School mostrou que $75 \%$ de todas as startups falham e que isso pode ser decorrente do uso de métodos tradicionais (BLANK, 2013).

Segundo Ries (2012), as startups ainda não sabem quem são seus clientes e como devem ser seus produtos. Além disso, ante as incertezas do mundo contemporâneo, prever o futuro é quase impossível, sendo preciso levar em conta, ainda, que as metodologias de administração antes utilizadas, hoje, não contemplam as necessidades que se apresentam. Planejamento e previsão são precisos e possíveis apenas quando baseados em um histórico operacional longo e estável e em um ambiente estático - e as startups não contemplam nenhum dos dois aspectos.

\section{MÉTODO}

No intuito de compreender o processo e as ações realizadas para abertura e gerenciamento de startups do interior do estado do Rio Grande do Sul, desenvolveu-se um estudo de natureza exploratória, com abordagem qualitativa. Como população-alvo definiram-se os sócios/ gestores de empresas startups da cidade de Santa Maria, localizada no Rio Grande do Sul. Com- 
puseram a amostra deste estudo sete sócios/gestores de empresas startups da cidade de Santa Maria, os quais são aqui denominados E1, E2, E3, E4, E5, E6 e E7, visando ao anonimato.

Para a coleta dos dados, utilizou-se um roteiro de entrevista semiestruturado, contendo 58 questões distribuídas em duas subdivisões. A primeira corresponde à obtenção de dados relativos ao perfil do entrevistado, e a segunda é referente ao modelo teórico adaptado de Reynolds (2000), o Databases for the Study of Entrepreneurship (Base de Dados para o Estudo do Empreendedorismo). Esse modelo abarca diversos construtos, que vão desde a ideia e concepção do negócio, perpassando pelo desenvolvimento das atividades da empresa, até suas perspectivas futuras.

Assim, considerando o objetivo deste artigo - compreender o processo e as ações realizadas para abertura e gerenciamento de startups -, foram escolhidos no modelo de Reynolds (2000) construtos que coadunassem com esse objetivo. Esses construtos foram alocados em categorias e variáveis, de modo que permitissem a articulação dos dados coletados e, assim, o alcance do objetivo do trabalho. 0 Quadro 1, a seguir, apresenta as categorias e variáveis definidas a partir do modelo supracitado.

Quadro 1 - Categorias e variáveis de coleta e análise dos dados

\begin{tabular}{|c|c|}
\hline \multirow{5}{*}{ Caracterização das startups } & Natureza do negócio (ramo de atuação) \\
\hline & Descrição das atividades do negócio \\
\hline & Tempo de empresa \\
\hline & Faturamento médio anual \\
\hline & Motivações para abertura do negócio \\
\hline \multirow{5}{*}{ Processo e ações de abertura do negócio } & Planejamento do negócio \\
\hline & Formação da equipe \\
\hline & Busca de conhecimento externo \\
\hline & Busca de assistência externa \\
\hline & Dificuldades encontradas \\
\hline \multirow{5}{*}{$\begin{array}{l}\text { Processo e ações de gerenciamento do ne- } \\
\text { gócio }\end{array}$} & Controles financeiros \\
\hline & Análise de mercado \\
\hline & Esforços de marketing \\
\hline & Vantagem competitiva \\
\hline & Perfil de gestão \\
\hline
\end{tabular}

Fonte: elaborado pelos autores com base em Reynolds (2000).

Como técnica de análise de dados, utilizou-se a análise de conteúdo, proposta por Bardin (2010), que consiste em um tipo de análise que visa obter indicadores que permitam a inferência de conhecimentos, por meio de procedimentos sistemáticos e objetivos de descrição do conteúdo das mensagens. Realizou-se, assim, uma análise categorial, baseada nas categorias e variáveis de análise que foram definidas anteriormente e apresentadas no Quadro 1. Para isso, após realizadas as entrevistas e as transcrições, efetuaram-se a codificação e análise do texto.

\section{ANÁLISE E DISCUSSÃO DOS RESULTADOS}

Por meio da análise dos resultados, buscou-se compreender o processo e as ações realizadas para abertura e gerenciamento de startups no interior do estado do Rio Grande do Sul. Sendo assim, a apresentação e a discussão dos resultados estão organizadas em três subseções: caracterização das startups; processo e ações de abertura do negócio; e processo e ações de gerenciamento do negócio. 


\subsection{Caracterização das startups}

Buscando caracterizar o perfil das startups pesquisadas, os gestores foram questionados quanto à natureza do negócio (ramo de atuação), às atividades do negócio (descrição das atividades específicas que a empresa desempenha), ao tempo de empresa (tempo de existência da empresa atuando no mercado), ao faturamento médio anual e às motivações para abertura do negócio. O Quadro 2 apresenta uma síntese dessas informações.

Quadro 2 - Caracterização das Startups.

\begin{tabular}{|c|c|c|c|c|}
\hline Entrevistado & $\begin{array}{l}\text { Ramo de atu- } \\
\text { ação }\end{array}$ & Descrição das atividades do negócio & $\begin{array}{l}\text { Tempo da } \\
\text { empresa }\end{array}$ & $\begin{array}{c}\text { Faturamento } \\
\text { anual (R\$) }\end{array}$ \\
\hline E1 & $\begin{array}{l}\text { Mercado Imobi- } \\
\text { liário }\end{array}$ & $\begin{array}{l}\text { Site que visa centralizar a busca de imobili- } \\
\text { árias, móveis e decorações, construtoras e } \\
\text { incorporadoras, arquitetos e engenheiros. } \\
\text { Procura intermediar as negociações entre } \\
\text { seus parceiros e potenciais clientes. }\end{array}$ & $\begin{array}{l}1 \text { ano e } 6 \\
\text { meses }\end{array}$ & $\begin{array}{c}\text { Em fase de } \\
\text { investimento }\end{array}$ \\
\hline E2 & Alimentício & $\begin{array}{l}\text { Site que disponibiliza estabelecimentos/ } \\
\text { restaurantes, cardápios e preços para pe- } \\
\text { didos on-line de comida, de forma prática, } \\
\text { rápida e inteligente. }\end{array}$ & 2 anos & $\begin{array}{c}\text { Em torno de } \\
\mathrm{R} \$ 60 \mathrm{mil}\end{array}$ \\
\hline E3 & $\begin{array}{l}\text { Marketing e Co- } \\
\text { municação web. }\end{array}$ & $\begin{array}{l}\text { Site de marketing e comunicação web } \\
\text { que, por meio de ofertas diárias e de um } \\
\text { clube de benefícios com descontos atrati- } \\
\text { vos em diversos produtos e serviços, con- } \\
\text { tribui para o desenvolvimento e a divulga- } \\
\text { ção das empresas locais. }\end{array}$ & 5 anos & $\begin{array}{c}\text { Mais de } \\
\mathrm{R} \$ 240 \mathrm{mil}\end{array}$ \\
\hline E4 & $\begin{array}{l}\text { Marketing e Co- } \\
\text { municação web. }\end{array}$ & $\begin{array}{l}\text { Um site de conteúdo esportivo, que divul- } \\
\text { ga as modalidades esportivas praticadas } \\
\text { em Santa Maria e no Brasil, aproximando } \\
\text { o esporte aos seus amantes e simpatizan- } \\
\text { tes. }\end{array}$ & $\begin{array}{c}2 \text { anos e } 7 \\
\text { meses }\end{array}$ & $\begin{array}{l}\text { Informação } \\
\text { não forneci- } \\
\text { da. }\end{array}$ \\
\hline E5 & $\begin{array}{l}\text { Mobilidade Ur- } \\
\text { bana }\end{array}$ & $\begin{array}{l}\text { Um aplicativo móvel que visa oferecer a } \\
\text { melhor opção de preço e local de esta- } \\
\text { cionamento para o cliente (motorista), } \\
\text { facilitando a vida dos motoristas e renta- } \\
\text { bilizando o negócio de empresas ligadas a } \\
\text { estacionamento. }\end{array}$ & 1 ano & $\begin{array}{l}\text { Em fase de in- } \\
\text { vestimento }\end{array}$ \\
\hline E6 & $\begin{array}{l}\text { Consultoria Am- } \\
\text { biental }\end{array}$ & $\begin{array}{l}\text { Uma empresa de consultoria, voltada à } \\
\text { prestação e intermediação de serviços de } \\
\text { engenharia e meio ambiente. }\end{array}$ & 4 anos & $\begin{array}{c}\text { Mais de } \\
\text { R\$ } 480 \text { mil }\end{array}$ \\
\hline E7 & $\begin{array}{l}\text { Alimentício e } \\
\text { Entretenimento }\end{array}$ & $\begin{array}{l}\text { Uma plataforma on-line (website e aplica- } \\
\text { tivo móvel) que possibilita maior controle, } \\
\text { facilidade e opções para seus clientes, atu- } \\
\text { ando nos mercados de alimentação, bebi- } \\
\text { das e ingressos on-line. }\end{array}$ & $\begin{array}{c}3 \text { anos e } 2 \\
\text { meses }\end{array}$ & $\begin{array}{l}\text { Informação } \\
\text { não fornecida }\end{array}$ \\
\hline
\end{tabular}

Fonte: elaborado pelos autores com base nos dados da pesquisa.

A partir dessas informações iniciais, identificou-se que seis empresas têm sua natureza voltada a serviços em Tecnologia de Informação, em diferentes segmentos (Mercado Imobiliário; Alimentício; Entretenimento; Marketing e Comunicação Web; e Mobilidade Urbana), e uma empresa atua em consultoria (Consultoria Ambiental). Com relação à descrição das atividades do negócio, de modo geral, as empresas disponibilizam seus serviços por meio de websites e/ou aplicativos móveis.

No que se refere ao tempo das empresas no mercado, elas possuem de um a cinco anos de existência, encontrando-se, portanto, em diferentes fases de desenvolvimento. Quanto ao faturamento médio anual, pode-se verificar que as empresas que estão em fase inicial, de um a dois 
anos, declaram ainda estarem investindo no negócio, enquanto que as empresas com mais de dois anos afirmaram possuir faturamento médio anual entre 60 mil reais e mais de 480 mil reais. Destaca-se que todas essas empresas passam ou já passaram pelo processo de incubação.

Ainda buscando caracterizar as empresas pesquisadas, foram investigados os motivos que levaram à abertura do negócio (variável motivações para abertura do negócio). Em suas falas, os gestores destacaram, em sua maioria, que a ideia surgiu a partir de problemas enfrentados no dia a dia por eles e/ou por pessoas próximas, que os levou à identificação de oportunidades de mercado, o que pode ser evidenciado nas falas de E1 e E2transcritas a seguir:

[...] pelo problema do nosso sócio. Ele tem uma lavagem automotiva ecológica e na época estava buscando um ponto [...] para colocar a sua franquia, e ele não achava de jeito nenhum. E daí de tanto procurar em site, em site... Ele achou o imóvel. Existia o imóvel... Só a forma de apresentar os imóveis é que tinha esse problema... Não tinha... Estava faltando! E a gente viu isso! (E1).

[...] eu tive esse problema de querer um lanche, e ter que procurar na internet, lugar, preço, ligar para o restaurante e estar ocupado... Daí percebi que deveria ter alguma coisa para facilitar a nossa vida como usuário (E2).

Além de identificar uma oportunidade de mercado, E6 diz que "[...] foi por necessidade, questão de tributação. [...] a abertura da empresa foi por tributação menor e também porque a oportunidade de mercado estava ali à vista". Assim, a necessidade de diminuir encargos fiscais também foi apontada como um dos motivos que levou à abertura do negócio.

Ainda, foi salientada pelos entrevistados a vontade de ter seu próprio negócio, como relata E3: "[...] Eu sempre tive essa vontade de ser empreendedor; o trabalho de final de curso foi em cima de empreendedorismo, relacionado à criatividade e à inovação sustentável, e foi aí que a ideia surgiu". Além disso, o fato de ser de uma família empreendedora também foi destacado, como menciona E2: "[...] Eu estudei sobre empreendedorismo, sobre startups. Mas, eu vim de uma família que empreende, então isso motivou bastante! [...] meu pai colaborou bastante... Me incentivou bastante para criar a empresa [...]".

Sumariamente, caracterizando as empresas startups investigadas, verificou-se que, de alguma forma, todas são voltadas a serviços em Tecnologia de Informação; possuem de um a cinco anos de existência - as que estão de um a dois anos no mercado ainda estão em fase de investimento no negócio, enquanto que as que possuem mais de dois anos de existência possuem faturamento médio mensal entre 60 e mais de 480 mil reais -; as principais motivações para a abertura do negócio foram os problemas que enfrentavam no dia a dia, o que, por conseguinte, direcionou-os à identificação de oportunidades de mercado, além da necessidade de diminuir encargos fiscais, da vontade de ter seu próprio negócio e do fato de serem de famílias empreendedoras.

\subsection{Processo e ações de abertura do negócio}

A fim de compreender o processo e as ações para iniciar uma empresa startup, os sete gestores foram questionados sobre planejamento do negócio (tempo gasto até a implementação da ideia, a existência de um plano de negócios e uma metodologia própria para esse tipo de empresa), formação da equipe (número de sócios e colaboradores), investimentos iniciais, busca de conhecimento externo, busca de assistência externa e dificuldades encontradas.

Em relação ao planejamento do negócio, todos os entrevistados destacaram que levaram cerca de quatro a seis meses para formular a ideia e colocá-la em prática. O entrevistado E1 destaca: 
"A gente gastou mais de seis meses pensando no projeto, para começar a participar de editais aqui para ser incubado e para despertar também aquele 'clim' de empreendedorismo, né?!". Já o E5 salienta que, "nesse período que a gente começou a conversar até o período que a gente entrou na incubadora, foi aprovado no processo seletivo, deu uns quatro a cinco meses, foi rápido".

Ainda no que concerne ao planejamento do negócio, os gestores também foram questionados sobre terem um plano de negócio e/ou alguma metodologia própria para a abertura e o desenvolvimento de uma startup. As sete empresas pesquisadas possuem um plano de negócios estruturado, que, conforme relatado pelos entrevistados, foi feito como requisito para participarem dos editais das incubadoras de que hoje fazem parte. Isso é evidenciado nas falas de E3 e E6:

A gente fez um plano de negócios pra entrar na incubadora. [...] Então em função disso a gente criou o plano de negócios, utilizando a metodologia do Sebrae (E3).

Eu participei do processo seletivo pra incubar a empresa e ali foi necessário montar um plano de negócios da empresa. Então ali foi feito a matriz estratégica, todo o planejamento estratégico, levantamento de patrimônio da empresa [...] Todo o plano de negócio da empresa pra poder concorrer nesse edital (E6).

Os entrevistados, além de terem estruturado um plano de negócios para suas startups, adotaram metodologias específicas para o negócio, como, por exemplo, o Business Model Canvas, conforme afirma E5:

Essa metodologia do Canvas de modelo de negócio a gente já utilizava [...] Eu considero muito útil, muito interessante, porque tu consegue visualizar o teu negócio numa folha só. E a gente realizava isso pra produtos separado, a gente tem um modelo de negócio de cada produto, assim no caso, e produtos que a gente pensa em lançar (E5).

Quanto à formação de uma equipe inicial para a abertura do negócio, as sete empresas pesquisadas foram estruturadas com dois a cinco sócios, dois a três estagiários e alguns colaboradores e, eventualmente, contratam terceirizados para serviços como programação dos sites, edição de vídeo e captação de filmagem e engenharia ambiental.

No que se refere aos investimentos iniciais, em geral, as empresas tiveram gastos relativamente baixos, conforme salienta o entrevistado E5: [...] "foi um valor que não foi um valor tão alto, [...] que deu pra gente diluir ao longo desse tempo e foi interessante. Às vezes as pessoas ficam com medo de buscar o seu próprio negócio, por causa do investimento". Os principais investimentos citados pelos gestores foram em equipamentos tecnológicos (computadores, tablets, impressoras, câmeras fotográficas etc.) e no desenvolvimento de softwares e plataformas on-line. Aqueles que não possuíam um desenvolvedor de software em sua equipe relataram que tiveram um investimento um pouco maior para contratar alguém para fazer seus sistemas. Também, foram apontados alguns gastos com materiais básicos de escritório e materiais gerais.

Já em relação à busca de conhecimento externo, todos os entrevistados relataram que investem continuamente em cursos para capacitação da equipe e buscam participar e apoiar eventos da área em que atuam - alguns dos gestores até promovem palestras em que contam sua experiência de administrar uma startup, dando dicas e incentivando outras pessoas a empreender. O entrevistado E5 compartilha uma dessas experiências: "Teve um curso de gestão empreendedora que eu fiz aqui, alguma coisa relacionada a ser empreendedor mesmo [...] foi assim, espetacular. [...] Eu nesse meio tempo fiz um curso de gerenciamento de projetos em Porto Alegre, achei muito válido, consegui aplicar vários processos aqui dentro da empresa. Em relação 
a demais cursos, muito por conhecimento, por experiência, por vivência [...]. E também outros eventos, como [...] TED, Y2B da AIESEC; inclusive nesse evento eu pude aprender muito e desenvolver minhas habilidades de empreendedorismo, liderança, então foi tudo interessante". O entrevistado E2 destaca a importância do networking para o negócio: "[...] Então, tu indo pra esses eventos, tu consegue conversar com as pessoas, ter outras ideias. Vendo as dificuldades que elas passam também. [...] Tu aprende muito com as dificuldades dos outros... Isso é importante".

Tais falas evidenciam que as redes de contatos entre os empreendedores são importantes, pois fornecem aos gestores um conjunto diversificado de informações, oportunidades de negócio, acesso a recursos escassos, entre outras possibilidades. Dessa forma, é crucial para o sucesso de um projeto empreendedor que não se atue de modo isolado, e sim com diversas interações e contatos externos (JACK et al., 2010).

Quando questionados sobre a assistência externa - se ao longo do processo de abertura do negócio tiveram ajuda de mais alguém que não estava diretamente envolvido, mas que foi importante no processo -, todos os gestores destacaram uma ou mais pessoas que contribuíram, incluindo amigos, familiares e profissionais especializados:

Meu pai colaborou bastante, me incentivou bastante pra criar a empresa. Desde lá, ele vem até hoje auxiliando, ajudando (E3).

Um amigo que foi o nosso web design, começou conosco, foi um dos incentivadores também e teve um papel fundamental na criação da nossa empresa (E4).

Teve uma designer que nos auxiliou muito, inclusive ela refez a nossa marca, [...] foi bem simples a ideia inicial e ela pegou e remodelou, ela deixou mais simples e mais moderno. [...] nós tivemos outros dois na área de ciências da computação e de sistema da informação que nos ajudaram a desenvolver todo o sistema por trás, do sistema web no caso por trás do aplicativo (E5).

Por último, quanto aos processos e às ações para abertura da startup, os gestores responderam perguntas relativas às principais dificuldades que encontraram nesse início. Os entrevistados E1, E6 e E7 destacam a aceitação dos clientes e empresários quanto à inovação como um dos principais problemas enfrentados:

A captação de novos clientes. [...] é um público bem fechado de acrescentar um novo negócio para mudar a rotina (E1).

Acredito que a maior dificuldade foi a forma de vender esse tipo de serviço técnico por ser de uma forma inovadora e ser um produto novo no mercado, tivemos dificuldade na forma de negociação de como vender aquilo (E6).

Uma cultura muito grande [...] tanto dos clientes como dos empresários. Então, os empresários acreditarem em uma empresa jovem, o empresário acreditar na tecnologia, sabe?! Então é um pouco complicada essa questão de cultura, que ao longo do tempo nós estamos tentando mudar (E7).

Já E2 evidencia a falta de recursos financeiros: "[...] a maior dificuldade é a parte financeira. [...] a gente iniciou acho que meio iludido [...] e não é bem assim a coisa, o mercado te mostra a realidade, como as coisas funcionam, [...] tu volta pra trás e começa a reformular teu projeto de novo".

A inexperiência e falta de conhecimento de gestão também são citadas pelos entrevistados. E6 destaca: "[...] no começo falta de experiência com as áreas, nós somos de uma área bastante técnica, no início nós não tínhamos tanto conhecimento em gestão, conhecimento de 
marketing, comercial, que ao longo do tempo nós fomos aprendendo e amadurecendo". E5 também salienta que passou por essa mesma dificuldade: "[...] no começo foi muito complicado; eram dois estudantes de engenharia elétrica tentando abrir uma empresa, que envolve toda essa área administrativa [...] E não só isso, a parte comercial, marketing, vendas etc".

A esse respeito, destaca-se que a literatura acerca dos fatores de sucesso do negócio de uma startup indica as competências de gestão como um fator relevante e decisivo, as quais consistem em um conjunto de apetências que abarcam a gestão de uma empresa, tais como gestão de risco, de recursos humanos e estratégica (ALLMAN et al., 2011). Porém, o que se nota é que o ramo de atuação das startups está atrelado à formação profissional de seus gestores, que, na maioria das vezes, detêm apenas o conhecimento técnico sobre o seu negócio e pouca experiência ou competências de gestão. Desse modo, tais gestores enfrentam dificuldades no processo de gerenciamento de recursos humanos, financeiros e estratégicos de suas startups e acabam tendo de buscar cursos e capacitações externas, conforme pôde ser evidenciado anteriormente.

Nesse sentido, o entrevistado E5 evidencia ainda, em sua fala, o excesso de burocracia dos órgãos públicos para a regularização da empresa e o quanto isso pode ser um empecilho ao processo: "Santa Maria está começando a se abrir pra inovação, mas o problema é que o processo é lento, apesar de tudo hoje funcionar de maneira mais rápida [...] acho que era possível abrir ainda mais, diminuir muito as burocracias e tudo mais, por exemplo. [...] eu passei a semana inteira fora daqui da empresa lidando com esse negócio do alvará; [...] eu acho que Santa Maria e região poderiam se desenvolver muito mais se muitas burocracias fossem evitadas".

Corroborando essa constatação, o estudo de Soares et al. (2015) aponta o excesso de carga tributária e as exigências exageradas, que acarretam um tempo demasiadamente extenso de abertura de um novo negócio, como as maiores dificuldades enfrentadas por empresas que estão iniciando seus negócios.

Sinteticamente, acerca do processo e das ações para iniciar uma startup, os gestores entrevistados mencionaram que: levaram cerca de quatro a seis meses para formular a ideia do negócio e colocá-la em prática; possuem um plano de negócios estruturado e adotaram metodologias específicas para o negócio; contaram com sócios, estagiários e alguns colaboradores e, eventualmente, contratam serviços terceirizados; fizeram investimentos iniciais relativamente baixos; investem continuamente em cursos para capacitação da equipe; contaram com a assistência, em geral, de amigos, familiares e profissionais especializados no início das atividades das startups; e, como principais dificuldades enfrentadas na abertura do negócio, citam a aceitação dos clientes e empresários quanto à inovação, a falta de recursos financeiros, a inexperiência e falta de conhecimento de gestão e o excesso de burocracia dos órgãos públicos para a regularização da empresa.

\subsection{Processo e ações de gerenciamento do negócio}

A fim de conhecer os processos e as ações realizadas pelos gestores para o gerenciamento das startups, foram feitos questionamentos relacionados às variáveis: controles financeiros, análise de mercado, esforços de marketing, vantagem competitiva e perfil de gestão.

Com relação aos controles financeiros, isto é, em que medida a empresa realiza controles de fluxo de caixa, planejamento financeiro, declarações de renda, entre outras ações, todos os entrevistados afirmaram realizar a contabilidade de sua startup, porém tal serviço é prestado por uma empresa especializada.

A partir das falas dos gestores, foi possível identificar que, para algumas empresas, o controle financeiro ainda não é a preocupação principal e está sendo realizado mais por uma obrigação e de modo informal, apesar de estarem buscando meios para efetuar esses controles, 
como evidenciou o E2: "[...] atualmente na empresa estão pegando um software da internet para ajudar no controle da parte financeira, mas, por enquanto, não tem ninguém que cuida disso, eu que vou fazer isso... Mas não é uma coisa que muito me importa agora".

Por outro lado, alguns gestores demostraram a preocupação com o registro e o acompanhamento das informações financeiras, tanto para mensurar o crescimento quanto para construir suas metas, conforme o entrevistado E1 - "[...] A gente faz as nossas metas e o nosso faturamento em cima (dos livros caixas)... A gente analisa ele, né?!” - e o entrevistado E5 -“[...] É extremamente necessário fazer isso e tu consegue mensurar teu crescimento também".

Com relação ao processo de análise de mercado, os entrevistados foram questionados sobre sua percepção atual do mercado em que atuam e a maneira como analisam esse mercado, para então, utilizar as informações no desenvolvimento de novas estratégias e explorar oportunidades. Algumas empresas apontaram que percebem o mercado em crescimento e favorável para o desenvolvimento de seus negócios, enquanto outras consideram a influência da política, o aumento da inflação e a recessão da economia como fatores que estão influenciando negativamente o mercado consumidor.

Três gestores, em especial, percebem o mercado em crescimento e visualizam oportunidades para seus negócios, são eles: E1 (Mercado Imobiliário), E6 (Consultoria Ambiental) e E7 (Ramo Alimentício e Entretenimento). Eles reconhecem os seus respectivos mercados como propícios ao crescimento e desenvolvimento e têm visões otimistas em relação às perspectivas futuras para seus negócios.

De modo contrário, E2 e E3 percebem o mercado enfraquecido, especialmente após as eleições de 2014, afirmando que as pessoas se encontram receosas para consumir, conforme destaca E3: "[...] hoje o pessoal tá mais receoso em gastar e também mais cauteloso em gastar. Então, eu vejo que o mercado tá mais para decréscimo do que pra aumento, infelizmente".

No que tange à maneira como analisam o mercado, a startup do E7 foi a única que evidenciou realizar um estudo e uma análise do mercado no qual está inserida, processo esse que permitiu identificar a oportunidade de desenvolver franquias e de explorar uma nova oportunidade mercadológica. E2 afirmou que realizou a análise da concorrência antes da abertura do negócio e que, a partir dessa análise, foi possível criar um diferencial em seu negócio, que diz respeito à automação de seu sistema. Já E4 afirmou que a análise mercadológica ocorre no dia a dia, quando a empresa implementa ações e analisa o retorno de tais ações, verificando o que pode ser melhorado ou potencialmente explorado.

No que concerne aos esforços de marketing, os entrevistados relataram os canais e/ ou veículos de comunicação que escolhem para promover e divulgar a empresa, bem como os processos empregados para registro de suas marcas ou patentes. Acerca dos canais e/ou veículos de comunicação, todos os entrevistados consideram a participação na feira de exposição local, que ocorre no pavilhão da inovação, uma forma de divulgar seus negócios, especialmente E1, que apontou que a sua startup teve um retorno de acesso e contatos após a participação na feira: "Foi um desafio para a gente... A gente participou lá... Cumprimos esta etapa. E estamos vendo hoje os fluxos de acesso. A gente viu que teve de 15 a $18 \%$ de aumento no site hoje... Em acesso e contato". Além disso, E1 mencionou que realiza eventos locais destinados ao seu ramo de atuação (imobiliário), e E4, da mesma forma, apontou utilizar eventos do segmento esportivo para divulgar a empresa, sobretudo um evento criado pela própria empresa, o que, segundo ele, é uma estratégia de marketing que vem trazendo potenciais retornos.

Ademais, os gestores afirmaram utilizar a ferramenta Google Analytics ${ }^{\circledR}$, a rede social Facebook $^{\circledast}$, parcerias com jornais locais, vídeos institucionais e mídias alternativas, como a distribuição de sacolinhas ecológicas com a logomarca da empresa, adesivos, flayers e panfletos. 
O gestor E3 afirmou reservar um valor mensal tanto para pagar uma agência de publicidade para cuidar da imagem de sua startup quanto para investir nos veículos de comunicação. Por outro lado, E6 afirmou não realizar nenhum tipo de publicidade, fazendo uso da propaganda boca-a-boca.

Ainda referente aos esforços de marketing, os entrevistados foram questionados quanto ao registro de suas marcas e ao registro de patente. E1, E5 e E6 afirmaram estar em processo de registro da marca, enquanto E3, E4 e E7 já possuem o registro de suas marcas. E7, inclusive, afirmou que já utiliza o símbolo de marca registrada $\left({ }^{\circledR}\right)$ junto à sua logomarca, sendo a única startup que está em processo de registro de patente.

Com relação à vantagem competitiva e ao modo como ela é explorada pelas startups pesquisadas, os entrevistados acreditam que o diferencial de seus negócios com quanto à concorrência está relacionado com: a qualidade técnica na prestação de seus serviços; o software desenvolvido; a quantidade de opções que seus sistemas oferecem ao cliente; a credibilidade do trabalho; o fato de ser um negócio inovador e que atende a uma necessidade das pessoas; e à própria forma de divulgar o seu negócio.

Os gestores acreditam, ainda, que a própria escolha da cidade para sediar a startup pode atuar como vantagem competitiva, visto que o local pode se tornar uma questão estratégica. As startups investigadas estão localizadas no centro do estado, o que diminui a distância de acesso às demais regiões, onde se concentra a maioria de seus clientes, conforme evidencia a fala do E6: "[...] a maioria dos clientes são da região, empresas da região; como não tem muita indústria aqui, nosso foco de prestação de serviços não está muito aqui, mas nos posicionamos nesta cidade também em função da distância entre os outros pontos do estado. Então no centro do estado fica fácil o deslocamento pra qualquer ponto do estado, temos clientes em [...] todas as regiões".

Ademais, dois dos entrevistados não identificam concorrentes diretos na cidade e, além de perceberem isso como uma vantagem competitiva, desenvolvem ações voltadas para seu mercado, a fim de fomentá-lo e desenvolvê-lo. A forma de comunicar o seu produto, utilizando um marketing criativo e inusitado, a empatia e flexibilidade na forma de tratamento com os parceiros da empresa, as parcerias com organizações não governamentais (ONGs), os diferenciais nos produtos visando à satisfação do cliente final, a preocupação com a questão sustentável e as iniciativas para explorar outros segmentos de clientes também foram aspectos ressaltados pelos entrevistados como formas de explorar suas vantagens competitivas.

Por fim, ainda abarcando o processo e as ações de gerenciamento do negócio, buscouse identificar o perfil dos gestores das startups, com o intuito de conhecer suas formações, suas experiências anteriores e as características do seu modo de gerenciar. Quanto à formação, os entrevistados são formados em Engenharia Ambiental (E6); Tecnologia da Informação (E1); Engenharia Eletricista (E5); Ciência da Computação (E7); Jornalismo (E4); e Administração (E3). Os entrevistados E1 e E2 afirmam ainda estarem cursando Administração e Tecnologia de Informação, respectivamente. E2 ressaltou, ainda, que cursou administração por dois ou três anos, mas acabou abandonando o curso.

Quanto às experiências profissionais anteriores à abertura do negócio, foram citados trabalho como funcionário público e carreira militar (E1); estágio durante a graduação e participação em grupos de pesquisa na instituição em que se formou (E5); participação em uma associação de estudantes de administração e estágios durante a graduação em uma empresa de calçados e em uma revenda de carros na cidade (E3) e trabalho na empresa familiar (E2). O E6 afirmou possuir somente quatro anos de experiência no mercado, adquirida após a abertura do negócio.

No que se refere ao estilo com que gerenciam seus negócios, alguns apontaram preferir criar novos produtos e processos a apenas melhorar os já existentes (E1, E4, E5 e E6). Já 
os E2, E3 e E7 apontaram que a cultura de nosso país está voltada a somente melhorar o que já existe, sendo difícil criar algo novo, que seja $100 \%$ inovação, principalmente pela falta de incentivo. A esse respeito, destacam-se as falas de E3 e E2: “[...] outro dia eu vi uma reportagem que falava sobre o Brasil em termos de inovação. Então a gente considerava a China como o país mais inovador, se não me falha a memória, depois Estados Unidos, enfim, vinha esse... O Brasil [...] tem zero por cento em inovação" (E3) e "[...] no Brasil a universidade não te forma pra tu ir pro mercado de trabalho... Pra tu inovar... Ela não te forma pra isso... Ela forma pra tu ser um acadêmico. [...] Os caras saem de lá (em outros países) prontos pra fazer um aplicativo... Pronto pra fazer uma empresa... Pra fazer um negócio se quiserem, né... A gente não... A gente não sai preparado pra isso. A gente sai preparado pra fazer um mestrado, fazer sei lá o que..." (E2).

No que tange às características pessoais para resolver problemas, a maioria dos entrevistados apontou que procura resolver os problemas à medida que eles vão surgindo, adotando, portanto, uma postura mais reativa. Já o E3 demonstrou ter uma atitude mais proativa ao buscar perceber uma situação e resolvê-la antes que esta se torne um problema: "[...] não consigo ver um meio assim ou insatisfeito com alguma coisa, eu prefiro parar tudo que a gente tá fazendo, sentar e conversar frente a frente com as pessoas pra realmente resolver aquilo que tá acontecendo".

Com relação à forma de gerenciar, na sua maioria, os entrevistados destacaram que se consideram pessoas práticas, que buscam propiciar um clima de autonomia e liberdade para os funcionários realizarem suas atividades. Ainda, o E3 ressaltou que se considera um líder carismático e que gosta de lidar com as pessoas. Da mesma forma, o E2 ressaltou essa preocupação com o modo de liderar a sua equipe, inclusive de gerenciar os erros, considerando estes parte natural do processo de aprendizado da equipe, como é possível verificar em sua fala:

O ser humano é feito pra errar... Tem que errar pra aprender [...] a gente, quando gerencia, a gente lida com pessoas, né... Tudo bem... Tu tem o teu negócio, mas são as pessoas que vão fazer o teu negócio andar, não é tu que vai fazer. Sozinho tu não vai fazer nada! Então tu precisa delas do teu lado pra fazer funcionar. Então tu tem que trazer elas pro teu lado... Tem que fazer, dar o melhor possível pra elas poder fazer isso e dar liberdade pra elas (E2).

Suscintamente, acerca dos controles financeiros, todos os entrevistados afirmaram realizar a contabilidade de sua startup por meio de serviço terceirizado de empresa especializada, e apenas uma empresa (E7) realiza, efetivamente, análise de mercado. Em termos de investimentos em marketing, as startups utilizam participação em eventos, mídias impressas, mídias na internet, ferramentas on-line e propaganda boca-a-boca. No que se refere à vantagem competitiva, os gestores consideram a qualidade técnica de seus produtos e serviços, a credibilidade, o potencial inovador do negócio, a forma de divulgar e comunicar o negócio, a escolha da cidade para sediar a startup, a empatia e a preocupação com a sustentabilidade como formas de explorar suas potencialidades. Por fim, a respeito do perfil dos gestores das startups, verificou-se que estes têm estilos orientados para a inovação, a praticidade e uma gestão voltada às pessoas; no entanto, adotam postura reativa no que tange à identificação e resolução de problemas. Esses são os principais resultados acerca do processo e das ações para o gerenciamento das startups.

\section{CONSIDERAÇÕES FINAIS}

Considerando o rápido crescimento do número de startups no Brasil e no mundo, veio à tona o seguinte direcionamento de pesquisa: compreender o processo e as ações realizadas para abertura e gerenciamento de startups do interior do estado do Rio Grande do Sul. Para tanto, fo- 
ram definidas e investigadas, baseando-se no modelo teórico de Reynolds (2000), três categorias de análise: caracterização das startups; processo e ações de abertura do negócio; e processo e ações de gerenciamento do negócio.

Na categoria caracterização das startups, foram investigadas as variáveis natureza do negócio (ramo de atuação), descrição das atividades do negócio, tempo de empresa, faturamento médio anual e motivações para abertura do negócio. Os resultados demonstraram que no geral essas empresas são voltadas a serviços em Tecnologia de Informação; possuem de um a cinco anos de existência; e têm faturamento médio mensal entre 60 e mais de 480 mil reais. Destacase, ainda, que todas essas empresas passaram ou estão passando pelo processo de incubação.

Considerando que o papel das incubadoras é oferecer infraestrutura e suporte gerencial, abrigando novos negócios por um período de tempo limitado, orientando os empreendedores quanto à gestão do negócio e sua competitividade e, consequentemente, protegendo o desenvolvimento de tais empresas em sua fase inicial, esse processo de incubação de uma startup é visto como algo natural e que contribui para potencializar as chances de sucesso desses novos empreendimentos.

Com relação às motivações para a abertura do negócio, de modo geral, os entrevistados destacaram que, com base em problemas vivenciados no dia a dia, identificaram uma oportunidade de negócio que os motivou à abertura de suas startups.

Acerca do processo e das ações de abertura do negócio, investigaram-se o planejamento do negócio, a formação da equipe, a busca de conhecimento externo, a busca de assistência externa e as dificuldades encontradas. Quanto ao planejamento do negócio, considera-se válido ressaltar que as startups investigadas desempenham a função administrativa de planejamento, o que, muitas vezes, é mencionado como algo não executável por empreendedores ou profissionais ligados à inovação. A ideia de que empreendedores não se valem de ferramentas tradicionais de gestão, como, por exemplo, do plano de negócios, mostrou-se uma falácia, visto que este foi utilizado e citado por todos os gestores entrevistados.

Evidenciou-se, ainda, que, para abertura de seus negócios, os gestores levaram cerca de quatro a seis meses para formular a ideia do negócio e colocá-la em prática. Para isso, contaram com uma equipe formada pelos sócios, pelos estagiários e por alguns colaboradores, contratando, quando necessário, serviços terceirizados. No que tange à busca de conhecimentos, todos os gestores apontaram investir continuamente em cursos para capacitação da equipe. Como principais dificuldades enfrentadas na abertura do negócio, de modo geral, citaram-se: aceitação dos clientes e empresários quanto à inovação, falta de recursos financeiros, inexperiência e falta de conhecimento de gestão e excesso de burocracia dos órgãos públicos para a regularização da empresa.

Normalmente, o ramo de atuação das startups está atrelado à formação profissional de seus gestores, que, na maioria das vezes, detêm apenas o conhecimento técnico sobre o seu negócio e pouca experiência ou competências de gestão, o que leva os gestores a enfrentar dificuldades no processo de gerenciamento de recursos humanos, financeiros e estratégicos de suas startups e, consequentemente, buscar cursos e capacitações externas ou até mesmo uma formação complementar. De certo modo, o processo de incubação serve para auxiliar nesse período inicial, tanto pela troca de experiência quanto pelo fornecimento de consultorias, cursos e capacitações.

Sobre o processo e as ações de gerenciamento do negócio, pesquisaram-se o controle financeiro, a análise de mercado, os esforços de marketing, a vantagem competitiva e o perfil de gestão. No que se refere aos controles financeiros, todos os entrevistados afirmaram realizar a contabilidade de sua startup por meio de serviço terceirizado de empresa especializada. No que concerne à vantagem competitiva, os gestores consideram a qualidade técnica de seus produtos 
e serviços, a credibilidade, o potencial inovador do negócio, a forma de divulgar e comunicar o negócio, a escolha da cidade para sediar a startup, a empatia e a preocupação com a sustentabilidade como formas de explorar suas potencialidades. Com relação aos investimentos em marketing, as startups utilizam participação em eventos, mídias impressas, mídias na internet, ferramentas on-line e propaganda boca-a-boca. Quanto ao perfil dos gestores das startups, verificou-se que estes têm estilos orientados para a inovação, a praticidade e uma gestão voltada às pessoas; no entanto, adotam postura reativa no que tange à identificação e resolução de problemas.

De modo geral, esta investigação demonstrou o perfil das startups do interior do estado do Rio Grande do Sul, bem como o processo e as ações para abertura e gerenciamento de negócios dessa natureza. Diante disso, considera-se que os objetivos propostos pela presente pesquisa foram alcançados.

Dessa forma, em termos práticos, espera-se que os resultados apresentados possam servir como fonte de informação para futuros empreendedores identificarem como ocorre o processo de abertura e gerenciamento de uma startup. Do ponto de vista teórico, esta pesquisa trouxe como contribuição preliminar a compreensão de que, no contexto das startups, a metodologia de gestão adotada pelos gestores entrevistados é similar, pois, conforme já citado, os entrevistados ressaltaram a utilização do plano de negócio. Além disso, conforme constatado, existe um número ainda limitado de publicações sobre esse tema, de modo que este estudo visa colaborar para a ampliação do campo.

Como limitações, considera-se o fato de que a pesquisa foi realizada somente em uma cidade, sugerindo-se, para pesquisas futuras, a realização da pesquisa com startups de diferentes cidades ou até mesmo diferentes estados, a fim de verificar se os achados serão condizentes com os encontrados neste estudo. Outra limitação é o elevado número de questões do roteiro de entrevistas, aspecto que deve ser revisto em pesquisas futuras, visando obter um melhor entendimento por parte dos entrevistados das questões colocadas, pois nem sempre as respostas foram ao encontro da informação esperada, existindo um esforço adicional para uniformizar os conceitos utilizados na comunicação entre entrevistado e entrevistador.

\section{REFERÊNCIAS}

\section{ABSTARTUPS. Associação Brasileira de Startups.} Disponível em: http://www.abstartups.com.br> Acesso em: novembro de 2014.

ALBERONE, M.; CARVALHO, R.; KIRCOVE, B. Sua ideia ainda não vale nada: o guia prático para começar a validar seu negócio. Rio de Janeiro, 2012.

BARDIN, L. Análise de conteúdo. Lisboa: Edições 70, 2010.

BLANK, S. Why the lean start-up changes everything. Harvard Business Review, 2013.

BLANK, S., DORF, B. The startup owne's manual: the step-by-step guide for building a great company. Califórnia: K\&S Ranch Press, 2012.
GITAHY, Y. O que é uma startup? São Paulo. 2010. Disponível em <http://exame.abril.com. $\mathrm{br} / \mathrm{pme} /$ dicas-de-especialista/noticias/o-quee-uma-startup $>$. Acesso em: outubro de 2014.

GITAHY, Y. O que é uma startup?2011. Disponível em: <http://www.sebrae.com.br/ sites/PortalSebrae/sebraeaz/O-que-\%C3\%A9uma startup\%3F>. Acesso em: novembro de 2014.

GRUBER, M.; MACMILLAN, I.C.; THOMPSON, J.D. Look before you leap: market opportunity identification in emerging technology firms. Management Science, v. 54, n. 9, p. 1652 1665, 2008.

HERMANSON, B. O que é uma startup? São Paulo: Mundo Sebrae, 2011. Disponível em: <http://www.mundosebrae.com.br/2011/01/ 
o-que-e-uma-startup/>. Acesso em dezembro de 2014.

HUNT, R.A. Entrepreneurial tweaking: an empirical study of technology diffusion through secondary inventions and design modifications by start-ups, European Journal of Innovation Management, v. 16, n. 2, p. 148-170, 2013.

INFOMONEY. Abrir uma startup não é tão fácil como parece. Disponível em:<http://www.infomoney.com. $\mathrm{br} /$ negocios/startups/noticia/3506090/abriruma-startup-nao-tao-facil-como-pareceacabam-fechando>. Acesso em: outubro de 2014.

LONGHI, F. A história da revolução das startups. Imasters, 2011. Disponível em: <http:// imasters.com.br/artigo/20027/mercado/ahistoria-da-revolucao-das-startups $>$. Acesso em dezembro de 2014.

MAURYA, A. Running lean. 1aedição, O'Reilly Media, Inc. EUA, 2010.

MORAES, M. R.; CAPELLARI, V. G. Metodologias Aplicadas em Startups Inovadoras no Desenvolvimento de Projetos de Sucesso. In: ANPROTEC, Anais.. XXIII Seminário Nacional de Parques Tecnológicos e Incubadoras de Empresas,2013.

NAGAMATSU, F. A; BARBOSA, J e REBECCHI, A. Business ModelGeneration e as contribuições na abertura de startups. In: Anais.. II Simpósio Internacional de Gestão de Projetos - SINGEP e Simpósio Internacional de Inovação e Sustentabilidade -S2IS. São Paulo, outubro de 2013.

OSTERWALDER, A.; PIGNEUR, Y. Business model generation, 2010.

REYNOLDS. P. D. Business Startups: Background and Methodology. Databases for the study of entrepreneurship, vol. 4, pages 153-227. Elsevier, 2000.

RIES, E. A startup enxuta. 1a ed. São Paulo:
Leya, 2012.

ROGERS, S. Finanças e estratégias de negócios para empreendedores. Porto Alegre: Bookman, 2011.

STARTUPBASE. Banco de dados da associação brasileira de startups. Disponível em: <http:// startupbase.net/stratup $>$. Acesso em: novembro de 2014

TEECE, D. J. Business models, business strategy and innovation, Long Range Planning, Vol. 43 No. 2, pp. 172-194, 2010.

ESTEVE-PÉREZ, S.; RODRÍGUEZ, D. The dynamics of exports and R\&D in SMEs. Small Business Economics, v. 41, n. 1, p. 219-240, 2013.

USMAN, M.; VANHAVERBEKE, W. How startups successfully organize and manage open innovation with large companies. European Journal of Innovation Management, v. 20, n. 1, p. 171-186, 2017.

ZACHARY, G. P. A geografia global da inovação. Disponível em: <http://www. embaixadaamericana.org.br/HTML/ ijse1109p/zachary.htm>. E-journal Embaixada Americana -Publicada em Wall Street Journal, Acesso em: novembro 2014. 